\title{
Application of the Rotor Field-Oriented Control for an Induction Motor Used in Electric Traction
}

\author{
Mihaela Popescu*, Alexandru Bitoleanu* and Constantin Vlad Suru* \\ *University of Craiova, Faculty of Electrical Engineering, Craiova, Romania, mpopescu@em.ucv.ro
}

DOI: 10.52846/AUCEE.2021.1.02

\begin{abstract}
In this paper, the rotor field-oriented control is applied for a three-phase induction motor used in electric traction of an autonomous locomotive powered by a battery. First, the operating equations in the rotor field-oriented system are introduced. Then, the control scheme based on the structural scheme and operational equations are presented. After referring to the design of the controllers, the performances of the control system during the start-up process by prescribing a ramp speed and step rotor flux are addressed and analyzed. Four values of the prescribed speed are taken into consideration. Through the presented results, the synthesis of the control system and control algorithm are validated.
\end{abstract}

Cuvinte cheie: control cu orientare după fluxul rotoric, tracțiune electrică, locomotivă autonomă, motor trifazat de inducție, regulator cu histerezis, regulator PI.

Keywords: rotor field-oriented control, electric traction, autonomous locomotive, three-phase induction motor, hysteresis controller, PI controller.

\section{INTRODUCTION}

In the 1970s, Haase [1] and Blaschke [2] introduced the so-called field-orientation technique applied to the induction motor, which involves decoupling the torque and magnetic flux as with the direct current motor. In a reference frame that rotates simultaneously with the rotor flux, the torque can be controlled by the q-axis component of the stator current vector.

The best known implementation of the rotor fieldoriented control is the indirect control. According to this, the rotor flux is estimated and not measured, based on the associated equations [3].

When the voltage control is taken into consideration, two control paths exist in the structure of the rotor fieldoriented control [4]-[6]. Within the first path, the external loop is of the speed and the subordinate loop is of the active current. In the second path, the external loop is of the rotor flux and the subordinate loop is of the reactive current.

The difficulty in the implementation of the voltage control consists of the need to design four controllers. But, if a control structure with current control is adopted, only two controllers remain in the system to be designed and the inverter control is performed by a hysteresis controller [6].

Among the challenges of implementing the rotor fieldoriented control, the accurate estimation of the motor parameters and ensuring the most precise control of the current's components are highlighted [7]-[14]. In [11], the proposed strategy involves the use of the rotor field- oriented model equations to estimate the electromagnetic torque and rotor resistance.

To estimate the rotor resistance, the authors of [10] designed a scheme based on the rotor flux model and fuzzy controller. In [14], a sensorless fuzzy logic based indirect vector control with an adaptation scheme for the rotor resistance using neural learning algorithm was taken into consideration.

An adaptive sliding-mode observer was proposed in [8], and the online adaptation of the rotor resistance was achieved. A sliding mode observer based on rotor-flux was presented in [12] and a predictive field-oriented controller was used.

To keep the speed and torque of the induction motor oriented on the rotor field during the supply voltage drop, a new control technique was analyzed in [13], in which the d-axis and q-axis current control is based on solving the voltage, current, and torque constraints in the current plane.

The results presented in this paper were obtained by carrying out the PACETSINEFEN project in the frame of POC program, European Regional Development Fund. The implementation of the proposed control system will be done on an electric traction physical model of a locomotive powered by a battery.

The next part of this paper is organized as follows. In section II, the operating equations and control scheme are presented. Next, the attention is directed to the synthesis of speed and rotor flux controllers. Then, section IV presents the performance of the system, in which, the start-up process by prescribing a ramp speed and a step rotor flux, for four prescribed speeds, are taken into consideration. The paper ends with some conclusions and future research directions.

\section{OPERATING EQUATIONS AND CONTROL SCHEME}

The equation of operation are expressed in the $(\mathrm{d}, \mathrm{q})$ reference frame with the d-axis oriented in the direction of the rotor flux (Fig. 1). As shown, the q-axis component of the rotor flux is zero. $\lambda$ is the angle between the rotating $(d, q)$ reference frame and the fixed reference frame $(\alpha, \beta)$.

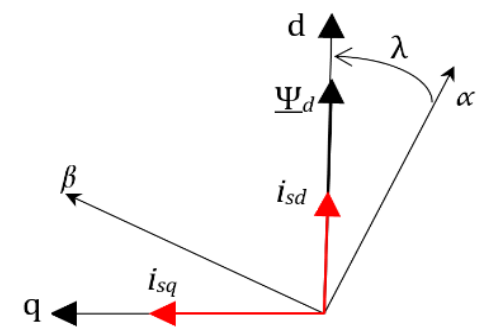

Fig. 1. Orientation of the rotating $(\mathrm{d}, \mathrm{q})$ reference frame. 
The following expression of the electromagnetic torque shows that, if the rotor flux is constant, the electromagnetic torque can be controlled only through the q-axis component of the rotor current.

$$
m=-\frac{3}{2} p \Psi_{r d} i_{r q} .
$$

The equations of the rotor circuit are [15]:

$$
\begin{gathered}
0=R_{r} i_{r d}+\frac{d}{d . t} \Psi_{r d} ; \\
0=R_{r} i_{r q}+\left(\omega_{1}-p \omega\right) \Psi_{r d},
\end{gathered}
$$

where the expressions of the rotor flux on the two axes are:

$$
\begin{gathered}
\Psi_{r d}=L_{r} \mathrm{i}_{r d}+L_{m} \mathrm{i}_{s d} ; \\
0=L_{r} \mathrm{i}_{r q}+L_{m} \mathrm{i}_{s q} .
\end{gathered}
$$

The equation of motion is added to the system of equations.

$$
J \frac{d \omega}{d . t}=-\frac{3}{2} p \Psi_{r d} \mathrm{i}_{r q}-m_{s} .
$$

The following quantities are used in equations (1) - (6): $\underline{i}_{r}, \underline{\Psi}_{r}$ - the spatial phasors of the rotor currents and rotor flux referred to the system $(\mathrm{d}, \mathrm{q})$; $m, m_{s}$ - the electromagnetic and static torque respectively; $R_{s}, R_{r}$ - the stator and rotor resistances referred to the stator;

$L_{r}$ - the inductance on a rotor phase referred to the stator;

$L_{m}$ - the magnetization inductance;

$p$ - the number of pole pairs;

$\omega$ - the angular velocity of the rotor;

$\omega_{1}$ - the electrical speed of the rotating coordinate system.

The adopted control structure shown in Fig. 2 involves the current control, which is easier to implement compared to the voltage control. As shown, to synthesize the control signals for transistors, a three-phase hysteresis controller (Hys) is used. The existence of two controllers ( $\mathrm{R} \omega$ for speed and $\mathrm{R} \psi$ for the rotor flux), the transformation blocks for the reference frame $((\mathrm{d}, \mathrm{q}) \rightarrow(\alpha, \beta)$ and $(\alpha, \beta) \rightarrow(a, b, c))$ and the speed transducer $(T \omega)$ is highlighted. The rotor flux is calculated based on the stator current and the motor speed and the position angle $\lambda$ of the rotating reference frame is calculated based on the sine and cosine functions, as follows [6], [15]:

$$
\cos \lambda=\frac{\Psi_{s \alpha}}{\left|\underline{\Psi}_{r}\right|} ; \quad \sin \lambda=\frac{\Psi_{s \beta}}{\left|\underline{\Psi}_{r}\right|} .
$$

As illustrated in Fig. 2, there are two independent control paths, for speed and active current control and for rotor flux and reactive current respectively.

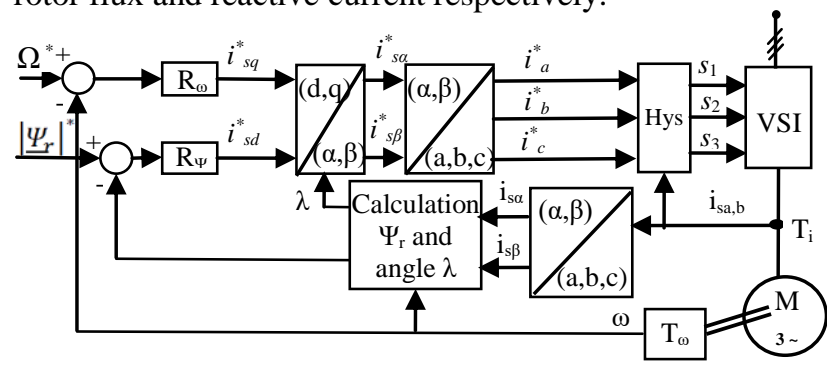

Fig. 2. Structure of the control system with current control.
In the first path, the prescribed active current is obtained at the output of the speed controller, whereas, in the second path, the prescribed reactive current is obtained at the output of the flux controller.

\section{SyNTHESIS OF SPEED AND ROTOR FLUX CONTROLLERS}

To express the involved transfer functions of the two controllers, the operational equations in the Laplace domain were used [6].

The parameters of the PI speed controller $\left(\theta_{1 \Omega}\right.$ and $\left.\theta_{\Omega}\right)$ which intervene in its transfer function,

$$
G_{R \omega}(\mathrm{s})=\frac{1+\mathrm{s} \theta_{1 \Omega}}{\mathrm{s} \theta_{\Omega}},
$$

were determined using the symmetry criterion [6].

$$
\theta_{1 \Omega}=4 T_{\Sigma} ; \quad \theta_{\Omega}=\frac{8 K_{f} T_{\Sigma}^{2}}{T_{m}},
$$

where $T_{\Sigma}$ is the dead time of the active current control loop (the sum of the speed transducer time constant and the sampling time $T_{s}$ ), the amplification factor $K_{f}$ is:

$$
K_{f}=\frac{3 p L_{m} \psi_{r N}}{2 L_{r}} \frac{\Omega_{N}}{T_{N}},
$$

and the mechanical time constant $\left(T_{m}\right)$ is:

$$
T_{m}=\frac{2 \mathrm{~J} L_{r} \Omega_{N}}{3 p L_{m} I_{N} \Psi_{r N}} .
$$

The parameters of the PI flux controller $\left(\theta_{1 \psi}\right.$ and $\left.\theta_{\psi}\right)$ in the transfer function,

$$
G_{R \Psi}(\mathrm{s})=\frac{1+\mathrm{s} \theta_{1 \Psi}}{\mathrm{s} \theta_{\Psi}}
$$

were provided by using the Modulus criterion in Kesller

\begin{tabular}{|c|c|c|c|c|c|c|c|c|}
\hline \multicolumn{9}{|c|}{ Inverter parameters } \\
\hline $\begin{array}{l}U_{\text {in }} \\
(\mathrm{V})\end{array}$ & $\begin{array}{l}U_{\text {Nout }} \\
\text { (V) }\end{array}$ & $\begin{array}{c}\boldsymbol{P}_{N} \\
\text { (kVA) }\end{array}$ & $\begin{array}{c}f_{N} \\
(\mathbf{H z})\end{array}$ & $\begin{array}{c}f \\
(\mathbf{H z})\end{array}$ & $\begin{array}{c}\mathbf{C}_{d} \\
(\mu \mathbf{F})\end{array}$ & $\begin{array}{l}\mathbf{U}_{C d N} \\
\text { (V) }\end{array}$ & \multicolumn{2}{|c|}{ IGBTs } \\
\hline 750 & 500 & 190 & 50 & $0-135$ & 1400 & 1800 & CM2400 & $-34 \mathrm{H}$ \\
\hline \multicolumn{9}{|c|}{ Traction motor rated parameters } \\
\hline $\begin{array}{l}U_{N} \\
(\mathbf{V})\end{array}$ & $\begin{array}{c}\boldsymbol{P}_{2 N} \\
(\mathbf{k W})\end{array}$ & $\begin{array}{c}f_{1 N} \\
{[(\mathbf{H z})}\end{array}$ & $\begin{array}{l}\boldsymbol{I}_{N} \\
\text { (A) }\end{array}$ & co & $\boldsymbol{\eta}_{N}$ & $\mathbf{s}_{N}$ & $\begin{array}{c}\boldsymbol{n}_{N} \\
(\mathbf{r p m})\end{array}$ & $\begin{array}{c}M_{N} \\
(\mathbf{N m})\end{array}$ \\
\hline 500 & 155 & 45 & 218 & 0.888 & 0.924 & 0.02518 & 1316 & 1125 \\
\hline $\begin{array}{c}R_{1} \\
(\Omega)\end{array}$ & $\begin{array}{l}X_{1 \mathrm{~N}} \\
(\Omega)\end{array}$ & $\begin{array}{c}L_{\sigma 1} \\
(\mathbf{m H})\end{array}$ & $\begin{array}{c}R_{2} \\
(\Omega)\end{array}$ & $\begin{array}{l}X_{2 N} \\
(\Omega)\end{array}$ & $\begin{array}{c}L_{\sigma 2} \\
(\mathrm{mH})\end{array}$ & $\begin{array}{l}R_{\mathrm{m}} \\
(\Omega)\end{array}$ & $\begin{array}{l}X_{\mathrm{m}} \\
(\Omega)\end{array}$ & $\begin{array}{c}L_{\mathbf{m}} \\
(\mathbf{m H})\end{array}$ \\
\hline 035 & 0.0621 & 0.2197 & 0.0358 & 0.067 & 0.2387 & 89.38 & 3.2507 & 11.497 \\
\hline
\end{tabular}
variant [6].

\section{CONTROL System PERFORMANCE}

The performance of the control system was assessed by using a specific Matlab-Simulink model developed for the experimental test platform. Table I summarizes the main parameters of the voltage source inverter and traction motor and Table II contains the parameters of the two controllers.

TABLE I.

MAIN PARAMETERS OF THE VOLTAGE SOURCE INVERTER AND TRACTION MOTOR

TABLE II.

PARAMETERS OF THE SPEED AND FLUX CONTROLLERS

\begin{tabular}{|c|c|c|c|c|c|}
\hline $\boldsymbol{K}_{p \Omega}$ & $\boldsymbol{T}_{\boldsymbol{i} \Omega}$ & $\boldsymbol{K}_{p \Omega}$ & $\boldsymbol{T}_{i \boldsymbol{\Omega}}$ & $\boldsymbol{K}_{p \psi}$ & $\boldsymbol{T}_{\boldsymbol{i} \psi}$ \\
\hline \multicolumn{2}{|c|}{$\Omega_{p} \geq \Omega_{N} / 2$} & \multicolumn{2}{|c|}{$\Omega_{p}<\Omega_{N} / 2$} & \multirow{2}{*}{36} & \multirow{2}{*}{0.32} \\
\cline { 1 - 3 } 100 & 0.003 & 200 & 0.004 & & \\
\hline
\end{tabular}


The ramp prescription of four speed values $\left(\Omega_{\mathrm{N}} / 10\right.$, $\Omega_{\mathrm{N}} / 2, \Omega_{\mathrm{N}}$ and $2 \Omega_{\mathrm{N}}$ ) and step rotor flux, at nominal resistive torque is considered.

The time evolution of speed, rotor flux, rotor flux components, electromagnetic torque, phase current and current components on the two axes are determined and analyzed. The main quantities during the steady-state operation are summarized for each case. To illustrate the performance of the control system, the following quantities were determined: rise time, settling time, maximum current and torque, overshoot, stator current distortion factor, efficiency and power factor.

\section{A. Performance in the case of prescribed speed of $0.1 \Omega_{N}$}

The time evolutions of the main quantities for the prescribed speed of $0.1 \Omega_{\mathrm{N}}$ are shown in Fig. 3 - Fig. 9.

Also, the main quantities during the steady-state operation are illustrated in Table III and the quantities that characterize control system performance are summarized in Table IV.

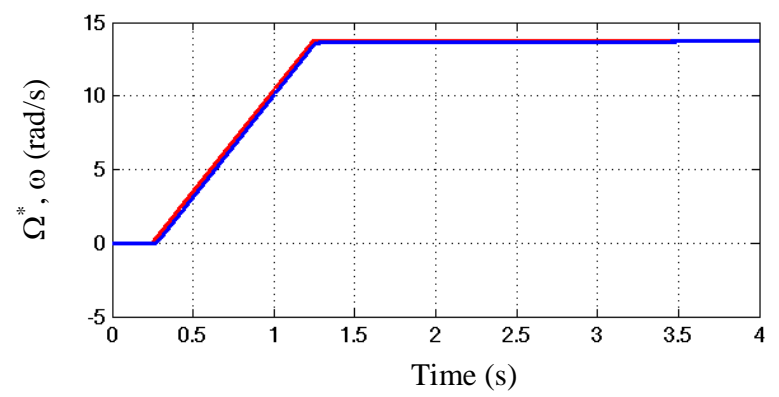

Fig. 3. Time evolution of the speed: prescribed speed $\left(\Omega_{N} / 10\right)-$ in red; actual speed - in blue.

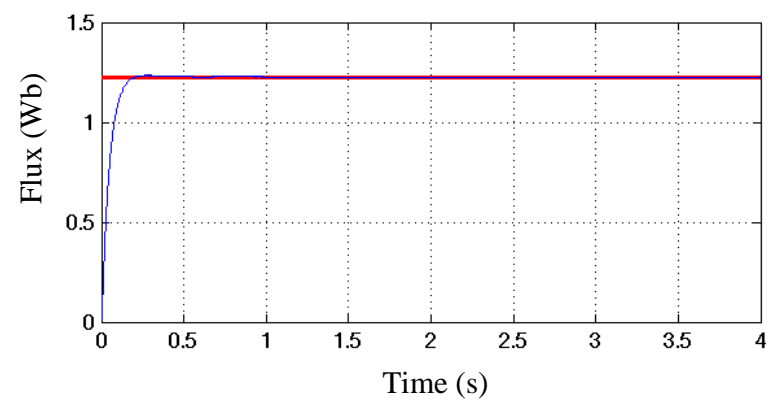

Fig. 4. Time evolution of the rotor flux for prescribed speed $\Omega_{N} / 10$ : prescribed value- in red; actual value - in blue.

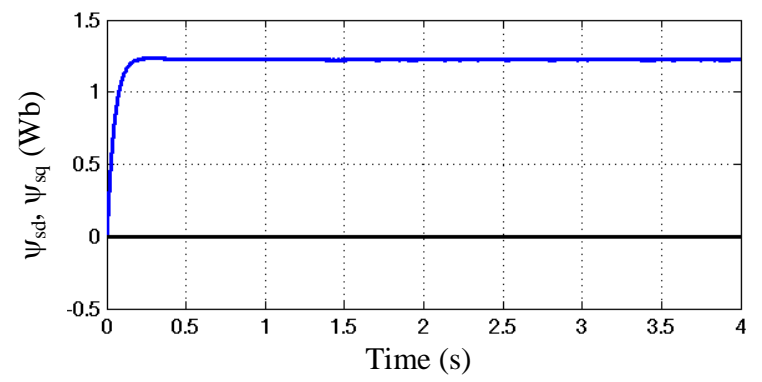

Fig. 5. Time evolution of the rotor flux components for prescribed speed $\Omega_{N} / 10$ : on the d axis - in blue; on the $\mathrm{q}$ axis - in black.

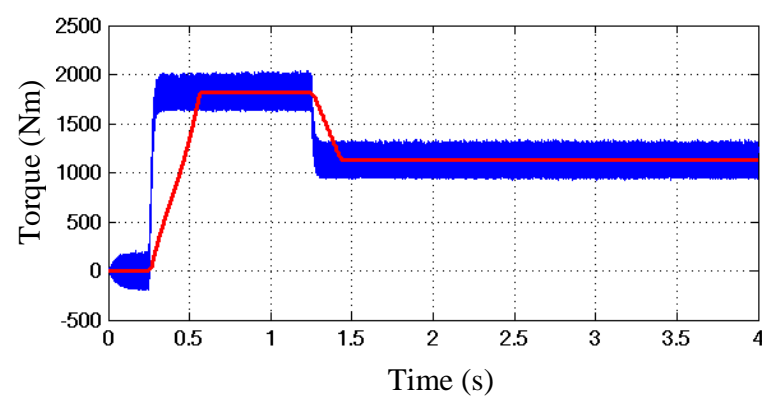

Fig. 6. Time evolution of the electromagnetic torque for prescribed speed $\Omega_{N} / 10$ : average torque - in red; actual torque - in blue.

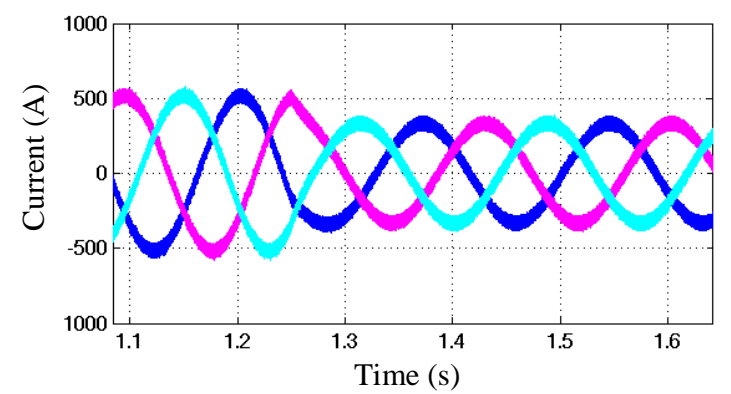

Fig. 7. Time evolution of the stator currents for prescribed speed $\Omega_{N} / 10$.

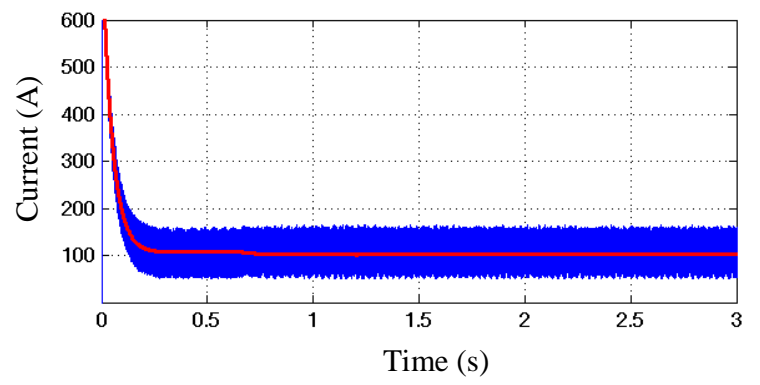

Fig. 8. Time evolution of the stator current component on the $\mathrm{d}$ axis for prescribed speed $\Omega_{N} / 10$ : prescribed value- in red; actual value- in blue.

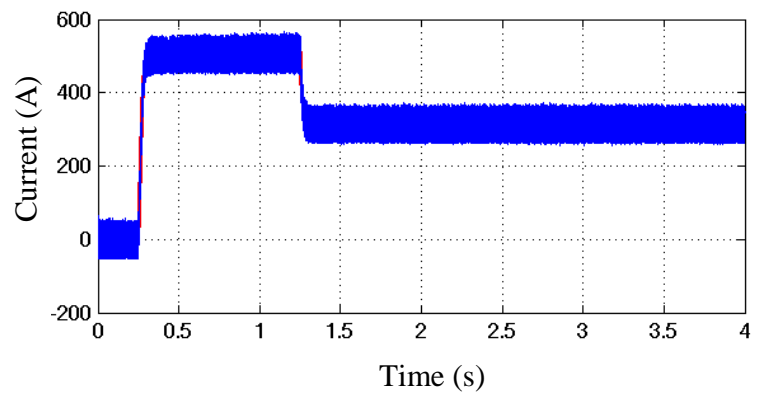

Fig. 9. Time evolution of the stator current component on the $\mathrm{q}$ axis for prescribed speed $\Omega_{N} / 10$ : prescribed value - in red; actual value - in blue.

TABLE III.

MAIN QUANTITIES IN STEADY STATE FOR PRESCRIBED SPEED $\Omega_{\mathrm{N}} / 10$

\begin{tabular}{|c|c|c|c|c|c|c|}
\hline $\boldsymbol{U}(\mathbf{V})$ & $\boldsymbol{U}_{\mathbf{1}}(\mathbf{V})$ & $\boldsymbol{I}(\mathbf{A})$ & $\boldsymbol{I}_{\mathbf{1}}(\mathbf{A})$ & $\boldsymbol{P}(\mathbf{k W})$ & $\boldsymbol{S}(\mathbf{k V A})$ & $\boldsymbol{P}_{\boldsymbol{m}}(\mathbf{k W})$ \\
\hline 377 & 40 & 235 & 234 & 17 & 266 & 15.4 \\
\hline
\end{tabular}

TABLE IV.

CONTROL PERFORMANCE FOR PRESCRIBED SPEED $\Omega_{\mathrm{N}} / 10$

\begin{tabular}{|c|c|c|c|c|c|c|}
\hline $\begin{array}{c}t_{c} \\
(\mathrm{~s})\end{array}$ & $\begin{array}{c}t_{r} \\
(\mathrm{~s})\end{array}$ & $I_{M} / I_{N}$ & $T_{M} / T_{N}$ & $\begin{array}{c}T H D_{I} \\
(\%)\end{array}$ & $\eta$ & $P F$ \\
\hline 1 & 4 & 1.8 & 1.6 & 12.33 & 0.9 & 0.064 \\
\hline
\end{tabular}




\section{B. Performance in the case of prescribed speed of} $0.5 \Omega_{N}$

In the case of prescribed speed of $0.5 \Omega_{\mathrm{N}}$, the time evolutions of the main quantities are presented in Fig. 10 Fig. 17. Table $\mathrm{V}$ shows the quantities specific to the steady-state operation and Table VI contains the indicators of the control system performance.

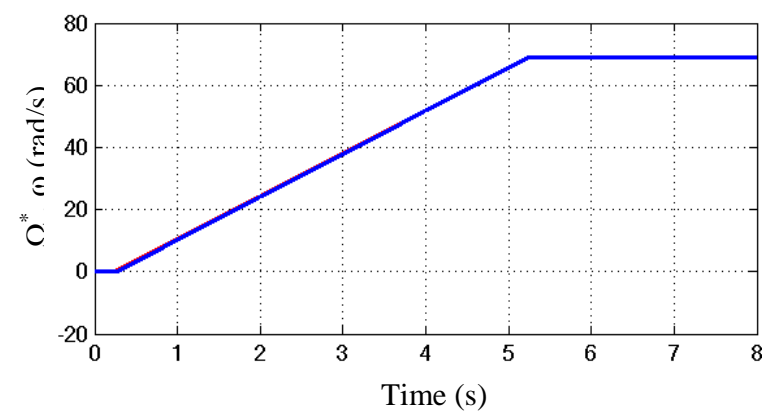

Fig. 10. Time evolution of the speed: prescribed speed $\left(\Omega_{N} / 2\right)$-in red; actual speed - in blue.

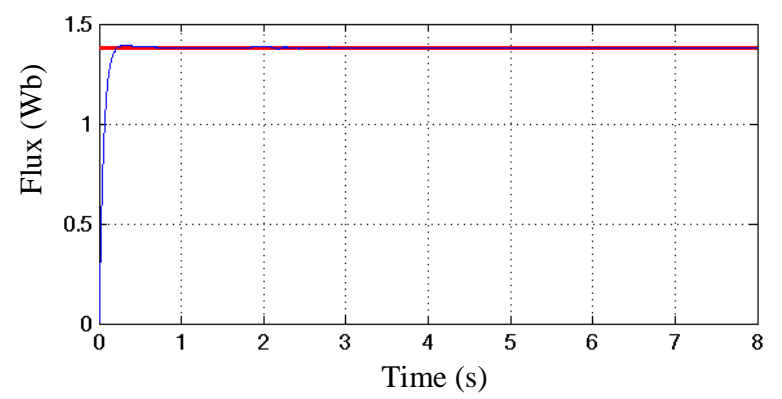

Fig. 11. Time evolution of the rotor flux for prescribed speed $\Omega_{N} / 2$ : prescribed value- in red; actual value - in blue.

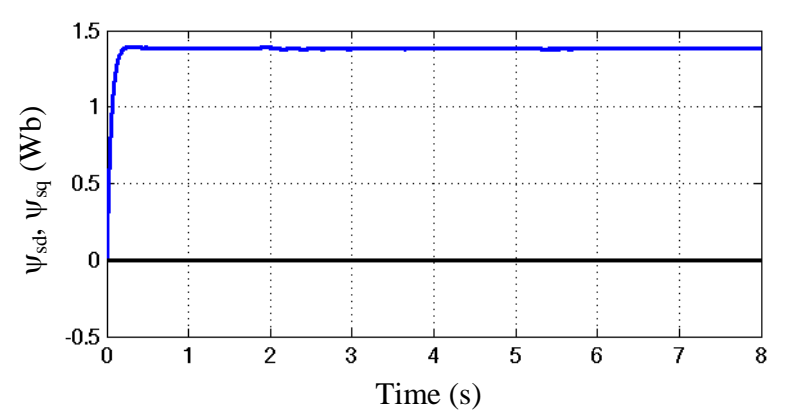

Fig. 12. Time evolution of the rotor flux components for prescribed speed $\Omega_{N} / 2$ : on the $\mathrm{d}$ axis - in blue; on the $\mathrm{q}$ axis - in black.

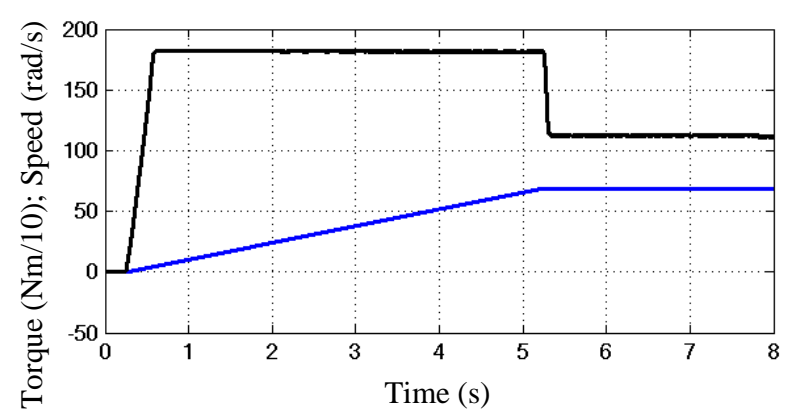

Fig. 13. Time evolution of the average electromagnetic torque (in black) and actual speed (in blue) for prescribed speed $\Omega_{N} / 2$.

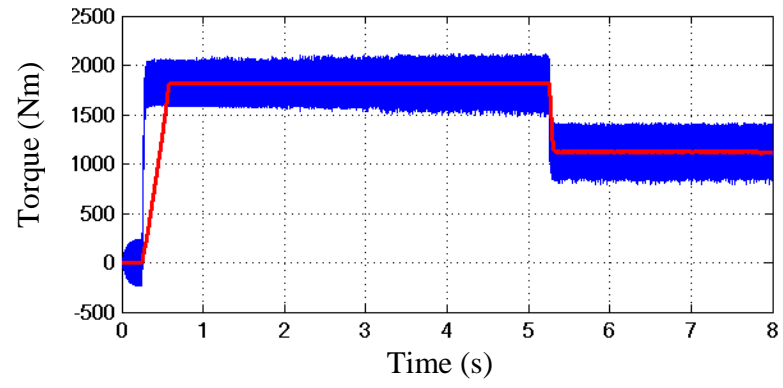

Fig. 14. Time evolution of the electromagnetic torque for prescribed speed $\Omega_{N} / 2$ : average torque - in red; actual torque - in blue.

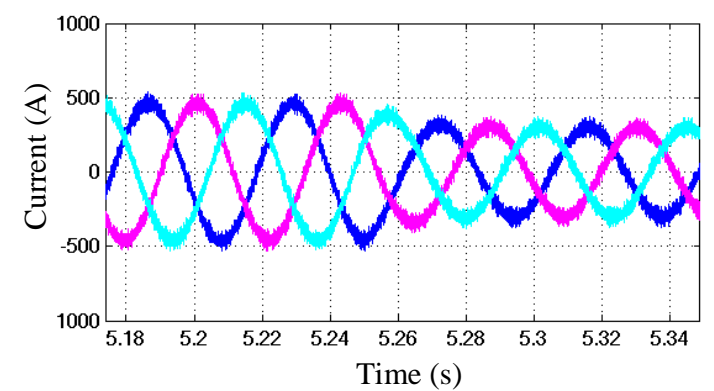

Fig. 15. Time evolution of the stator currents for prescribed speed $\Omega_{N} / 2$.

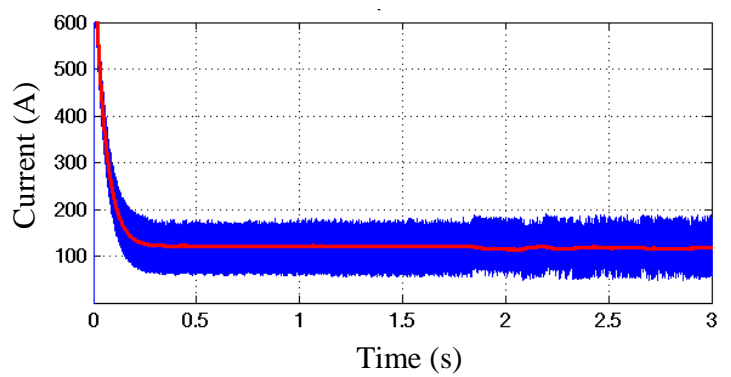

Fig. 16. Time evolution of the stator current component on the $d$ axis for prescribed speed $\Omega_{N} / 2$ : prescribed value-in red; actual value- in blue.

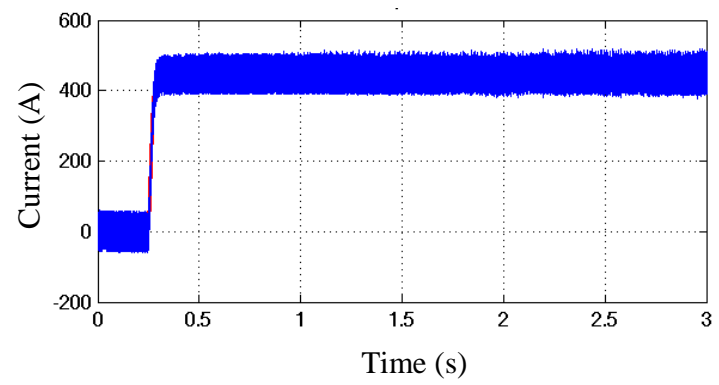

Fig. 17. Time evolution of the stator current component on the $\mathrm{q}$ axis for prescribed speed $\Omega_{N} / 2$ : prescribed value - in red; actual value - in blue.

TABLE V.

MAIN QUANTITIES IN STEADY STATE FOR PRESCRIBED SPEED $\Omega_{\mathrm{N}} / 2$

\begin{tabular}{|c|c|c|c|c|c|c|}
\hline $\boldsymbol{U}(\mathbf{V})$ & $\boldsymbol{U}_{\mathbf{1}}(\mathbf{V})$ & $\boldsymbol{I}(\mathbf{A})$ & $\boldsymbol{I}_{\mathbf{1}}(\mathbf{A})$ & $\boldsymbol{P}(\mathbf{k W})$ & $\boldsymbol{S}(\mathbf{k V A})$ & $\boldsymbol{P}_{\boldsymbol{m}}(\mathbf{k W})$ \\
\hline 376 & 138 & 233 & 231 & 80 & 263 & 71 \\
\hline
\end{tabular}

TABLE VI.

CONTROL PERFORMANCE FOR PRESCRIBED SPEED $\Omega_{\mathrm{N}} / 2$

\begin{tabular}{|c|c|c|c|c|c|c|}
\hline $\begin{array}{c}t_{c} \\
(\mathrm{~s})\end{array}$ & $\begin{array}{c}t_{r} \\
(\mathrm{~s})\end{array}$ & $I_{M} / I_{N}$ & $T_{M} / T_{N}$ & $\begin{array}{c}T H D_{I} \\
(\%)\end{array}$ & $\eta$ & $P F$ \\
\hline 5.6 & 5.6 & 1.8 & 1.8 & 12.42 & 0.94 & 0.31 \\
\hline
\end{tabular}




\section{Performance in the case of prescribed speed of $\Omega_{N}$}

For the case of prescribing the nominal speed, Table VII illustrates the main quantities which characterize the steady state regime and the time evolution of the quantities of interest is shown in Fig. 18 - Fig. 25. The control performance for the prescribed nominal speed is contained in Table VIII.

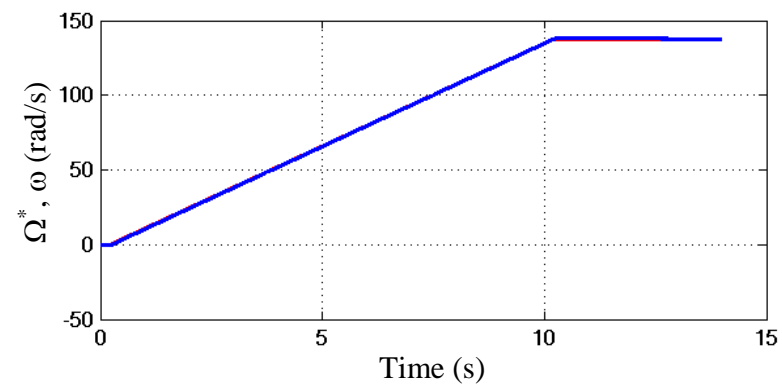

Fig. 18. Time evolution of the speed: prescribed speed $\left(\Omega_{N}\right)$-in red; actual speed - in blue.

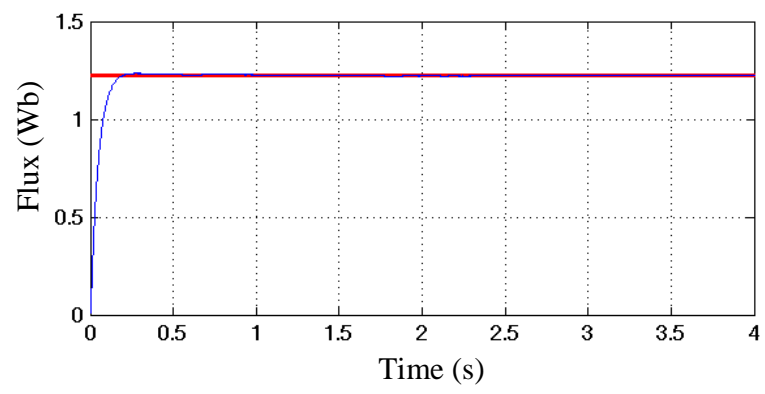

Fig. 19. Time evolution of the rotor flux for prescribed speed $\Omega_{N}$ : prescribed value- in red; actual value - in blue.

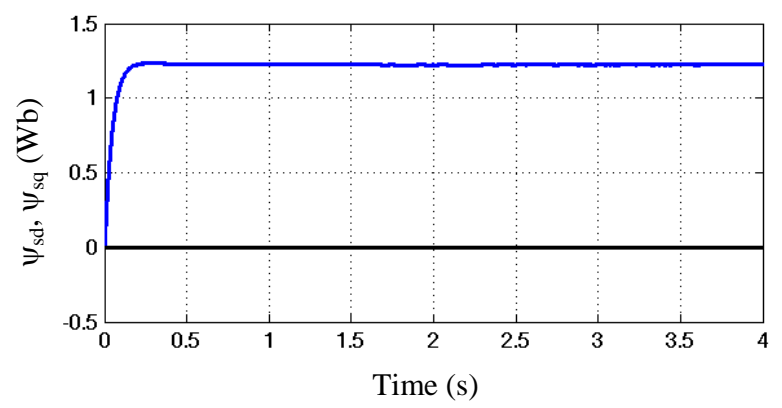

Fig. 20. Time evolution of the rotor flux components for prescribed speed $\Omega_{N}$ : on the $\mathrm{d}$ axis - in blue; on the q axis - in black.

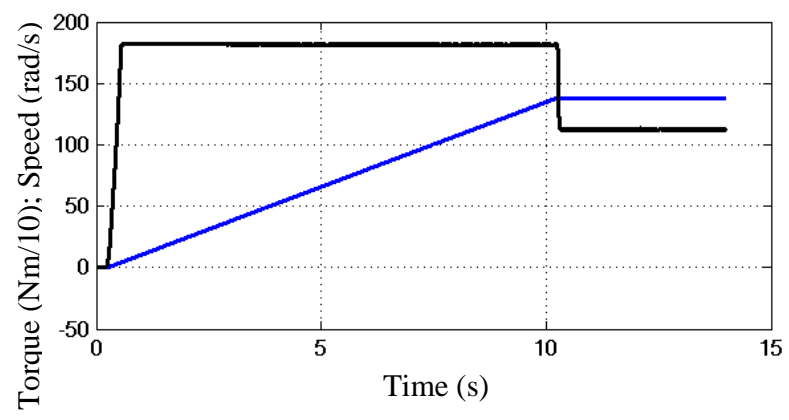

Fig. 21. Time evolution of the average electromagnetic torque (in black) and actual speed (in blue) for prescribed speed $\Omega_{N}$.

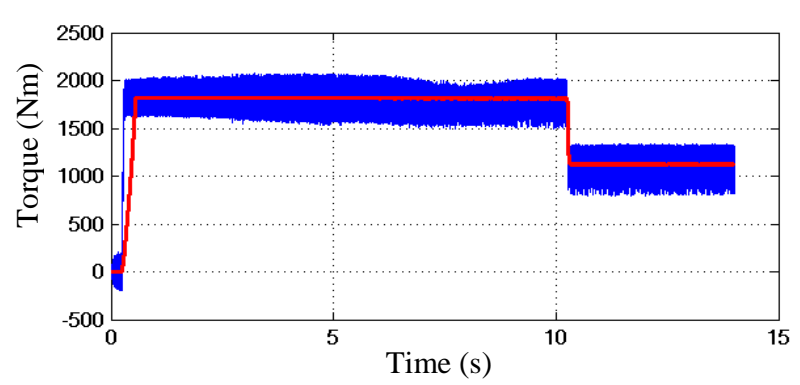

Fig. 22. Time evolution of the electromagnetic torque for prescribed speed $\Omega_{N}$ : average torque - in red; actual torque - in blue.

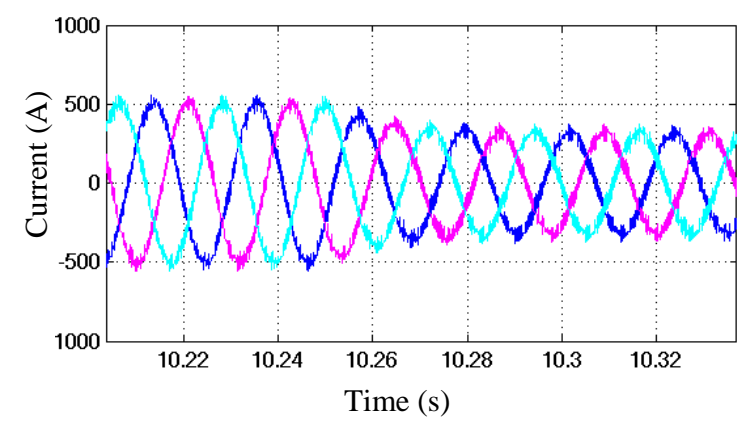

Fig. 23. Time evolution of the stator currents for prescribed speed $\Omega_{N}$.

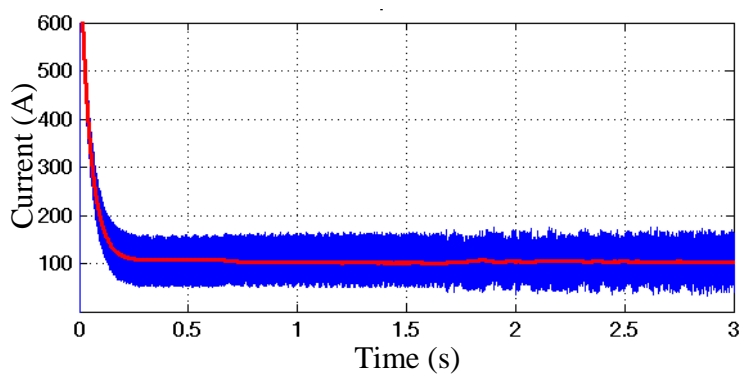

Fig. 24. Time evolution of the stator current component on the $\mathrm{d}$ axis for prescribed speed $\Omega_{N}$ : prescribed value- in red; actual value- in blue.

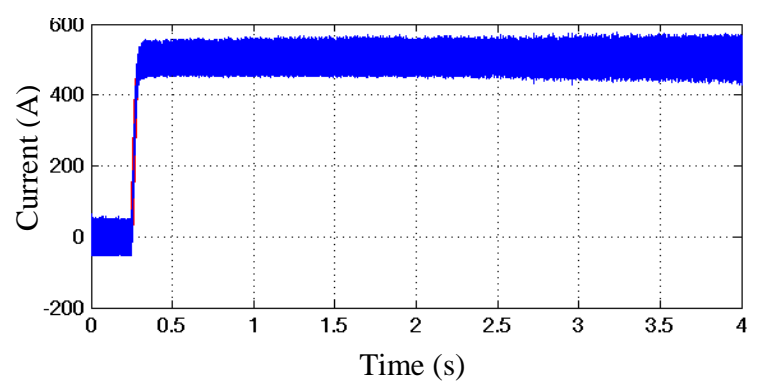

Fig. 25. Time evolution of the stator current component on the $\mathrm{q}$ axis for prescribed speed $\Omega_{N}$ : prescribed value - in red; actual value - in blue.

TABLE VII.

MAIN QUANTITIES IN STEADY STATE FOR PRESCRIBED SPEED $\Omega_{\mathrm{N}}$

\begin{tabular}{|c|c|c|c|c|c|c|}
\hline $\boldsymbol{U}(\mathbf{V})$ & $\boldsymbol{U}_{\mathbf{1}}(\mathbf{V})$ & $\boldsymbol{I}(\mathbf{A})$ & $\boldsymbol{I}_{\mathbf{1}}(\mathbf{A})$ & $\boldsymbol{P}(\mathbf{k W})$ & $\boldsymbol{S}(\mathbf{k V A})$ & $\boldsymbol{P}_{\boldsymbol{m}}(\mathbf{k W})$ \\
\hline 378 & 264 & 225 & 223 & 160 & 254 & 155 \\
\hline \multicolumn{8}{|c|}{ TABLE VIII. }
\end{tabular}

CONTROL PERFormANCE FOR PRESCRIBED SPEED $\Omega_{\mathrm{N}}$

\begin{tabular}{|c|c|c|c|c|c|c|}
\hline $\begin{array}{c}t_{c} \\
(\mathrm{~s})\end{array}$ & $\begin{array}{c}t_{r} \\
(\mathrm{~s})\end{array}$ & $I_{M} / I_{N}$ & $T_{M} / T_{N}$ & $\begin{array}{c}T H D_{I} \\
(\%)\end{array}$ & $\eta$ & $P F$ \\
\hline 10 & 10 & 1.8 & 1.6 & 11.4 & 0.94 & 0.63 \\
\hline
\end{tabular}




\section{Performance in the case of prescribed speed of $2 \Omega_{N}$}

When $2 \Omega_{N}$ is prescribed, the steady-state regime is characterized by the quantities illustrated in Table IX. How the quantities of interest evolve over time is presented in Fig. 26 - Fig. 32.

The system performance for the prescribed speed of $2 \Omega_{N}$ is summarized in Table $\mathrm{X}$.

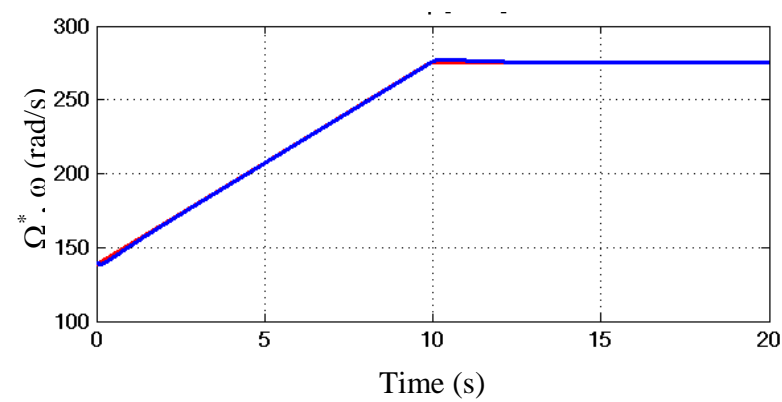

Fig. 26. Time evolution of the speed: prescribed speed $\left(2 \Omega_{N}\right)-$ in red; actual speed - in blue.

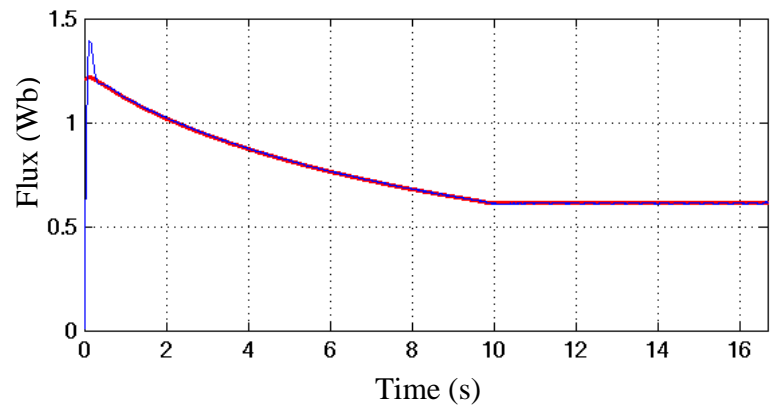

Fig. 27. Time evolution of the rotor flux for prescribed speed $2 \Omega_{N}$ : prescribed value- in red; actual value - in blue.

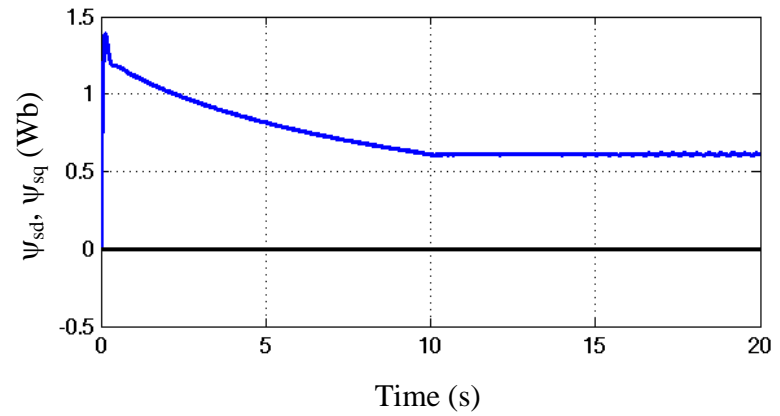

Fig. 28. Time evolution of the rotor flux components for prescribed speed $2 \Omega_{N}$ : on the $\mathrm{d}$ axis - in blue; on the q axis - in black.

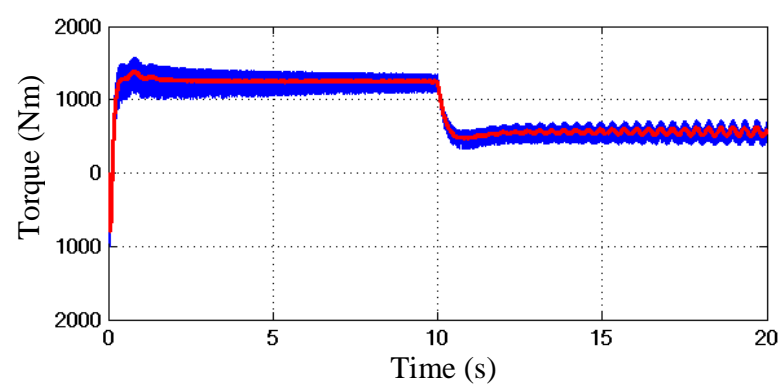

Fig. 29. Time evolution of the electromagnetic torque for prescribed speed $2 \Omega_{N}$ : average torque - in red; actual torque - in blue.

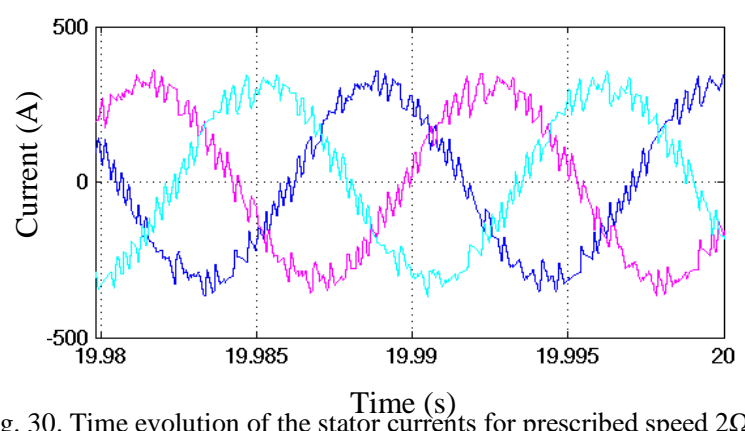

ig. 30. Time evolution of the stator currents for prescribed speed $2 \Omega_{N}$

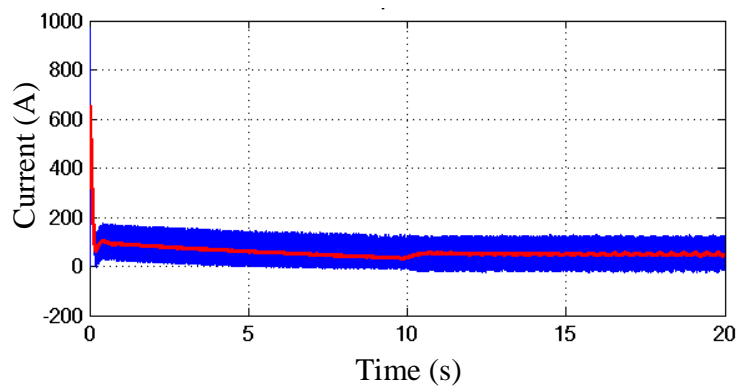

Fig. 31. Time evolution of the stator current component on the $\mathrm{d}$ axis for prescribed speed $2 \Omega_{N}$ : prescribed value- in red; actual value- in blue.

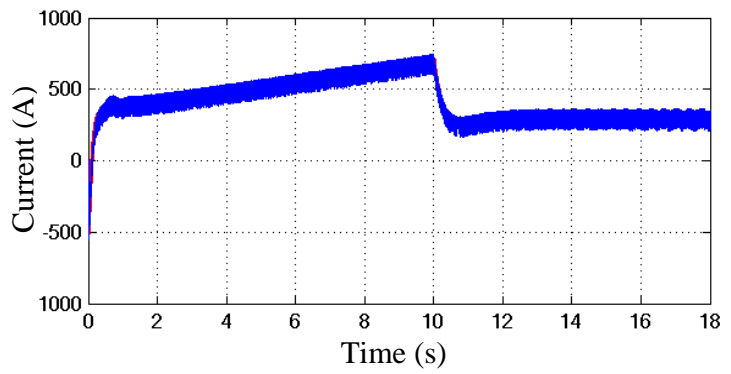

Fig. 32. Time evolution of the stator current component on the $q$ axis for prescribed speed $2 \Omega_{N}$ : prescribed value - in red; actual value - in blue.

TABLE IX.

MAIN QUANTITIES IN STEADY STATE FOR PRESCRIBED SPEED $2 \Omega_{\mathrm{N}}$

\begin{tabular}{|c|c|c|c|c|c|c|}
\hline $\boldsymbol{U}(\mathbf{V})$ & $\boldsymbol{U}_{\mathbf{1}}(\mathbf{V})$ & $\boldsymbol{I}(\mathbf{A})$ & $\boldsymbol{I}_{\mathbf{1}}(\mathrm{A})$ & $\boldsymbol{P}(\mathbf{k W})$ & $\boldsymbol{S}(\mathbf{k V A})$ & $\boldsymbol{P}_{\boldsymbol{m}}(\mathbf{k W})$ \\
\hline 371 & 269 & 225 & 224 & 168 & 250 & 155 \\
\hline
\end{tabular}

TABLE $X$.

CONTROL PERFoRMANCE FOR PRESCRIBED SPEED $2 \Omega_{\mathrm{N}}$

\begin{tabular}{|c|c|c|c|c|c|c|}
\hline $\begin{array}{c}t_{c} \\
(\mathrm{~s})\end{array}$ & $\begin{array}{c}t_{r} \\
(\mathrm{~s})\end{array}$ & $I_{M} / I_{N}$ & $T_{M} / T_{N}$ & $\begin{array}{c}T H D_{I} \\
(\%)\end{array}$ & $\eta$ & $P F$ \\
\hline 20 & 20 & 2.98 & 1.42 & 11.14 & 0.94 & 0.667 \\
\hline
\end{tabular}

\section{E. Results analysis}

The time evolution of the speed shown in Fig. 2, Fig. 10, Fig. 18 and Fig. 26 illustrates that the actual speed accurately follows the prescribed speed and there is only a very small overshoot. This overshoot is higher at high speed, but it does not exceed $0.04 \%$.

It can be seen that the rotor flux has a fast increase (Fig. 3, Fig. 11, Fig. 19 and Fig. 27) and a higher short-term overshoot occurs at high speed (for speed over the nominal value). Then, the prescribed value is very well followed.

The component of the rotor flux on the $\mathrm{q}$ axis is always zero (Fig. 4, Fig. 12, Fig. 20 and Fig. 28), which confirms the good orientation of the system according to the rotor flux. 
As shown in Fig. 6, Fig. 14, Fig. 22 and Fig. 29, the electromagnetic torque has a fast increase too. Its maximum value is of $1.8 T_{N}$ for $0.5 \Omega_{\mathrm{N}}$ and of $1.42 T_{N}$ for $2 \Omega_{\mathrm{N}}$ (Table XI). Also, high ripple of the electromagnetic torque is highlighted even during the steady-state operation.

The stator current increases rapidly to a maximum value of about $1.8 \mathrm{I}_{\mathrm{N}}$ for prescribed speeds below the nominal value and of about $3 \mathrm{I}_{\mathrm{N}}$ for high prescribed speed (Fig. 7, Fig. 15, Fig. 23, Fig. 31 and Table XI). There are ripples in the current waveform due to the variable switching frequency $(2.5-4 \mathrm{kHz})$.

In terms of performance indicators during the steadystate operation, the power factor has a very low value (about 0.064) at the lowest speed and increasing values with increasing prescribed speed (about 0.667 for the highest speed), as shown in Table XI. The efficiency value is 0.9 for the lowest prescribed speed and 0.94 for higher speeds (Table XI). The total harmonic distortion factor of the stator current is quite high (about $12 \%$ at low speeds and $11 \%$ at high speeds) - Table XI.

TABLE XI.

SYNTHESIS OF CONTROL PERFORMANCE INDICATORS FOR ALL PRESCRIBED SPEEDS

\begin{tabular}{|c|c|c|c|c|c|c|c|}
\hline & $\begin{array}{c}t_{c} \\
(\mathrm{~s})\end{array}$ & $\begin{array}{c}t_{r} \\
(\mathrm{~s})\end{array}$ & $I_{M} / I_{N}$ & $T_{M} / T_{N}$ & $\begin{array}{c}T H D_{I} \\
(\%)\end{array}$ & $\eta$ & $P F$ \\
\hline $0.1 \Omega_{\mathrm{N}}$ & 1 & 4 & 1.8 & 1.6 & 12.33 & 0.9 & 0.064 \\
\hline $0.5 \Omega_{\mathrm{N}}$ & 5.6 & 5.6 & 1.8 & 1.8 & 12.42 & 0.94 & 0.31 \\
\hline$\Omega_{\mathrm{N}}$ & 10 & 10 & 1.8 & 1.6 & 11.4 & 0.94 & 0.63 \\
\hline $2 \Omega_{\mathrm{N}}$ & 20 & 20 & 2.98 & 1.42 & 11.14 & 0.94 & 0.667 \\
\hline
\end{tabular}

\section{CONCLUSIONS}

The good results presented in this paper validate both the proposed control algorithm and the synthesis of the control system.

Starting from the observation that the switching frequency is not constant during the system operation (it varies from about $2.5 \mathrm{kHz}$ in steady-state regime to about 4 $\mathrm{kHz}$ in transient regime), the adoption of a variable hysteresis band for the current controller would be necessary.

In order for the prescribed speed ramp to be tracked, it is necessary to adapt the speed controller parameters according to the prescribed speed range. By using the designed parameters of the speed controller for prescribed speed over $\Omega_{N} / 2$, good performance in speed tracking is obtained. At lower prescribed speeds, however, keeping the same speed controller parameters leads to the inability for the prescribed speed ramp to be accurately followed, but the performance in steady state regime remains good.

The next stage of the research will be directed towards the use of an adaptive speed controller and the implementation the proposed control system on an experimental setup, which is being worked on.

\section{ACKNOWLEDGMENT}

This work was performed through Competitiveness Operational Program, project PACETSINEFEN, ID: P_40_196/105687, (2016-2021), European Regional Development Fund.

Source of research funding in this article: POC Program, project PACETSINEFEN.
Contribution of authors:

First author $-50 \%$

First coauthor $-30 \%$

Second coauthor $-20 \%$

Received on July 29, 2021

Editorial Approval on November 30, 2021

\section{REFERENCES}

[1] K. Hasse, "Zur Dynamik drehzahlgeregelter Antriebe mit Stromrichtergespeisten Asynchronkurzschlufermotoren," Ph.D. dissertation, T. U. Darmstadt, 1969.

[2] F. Blaschke, "The principle of field orientation as applied to the new transvector closed loop control system for rotating field machines," Siemens Rev, vol. 39, no. 5, pp. 217-220, May 1972.

[3] P. C. Valencia-Manrique and R. Jesus Coaquira-Castillo, "Speed performance comparative of indirect field oriented control based on current model for induction motors in educational equipment," in Proc. 2020 IEEE XXVII International Conference on Electronics, Electrical Engineering and Computing, 2020, pp. 1-4.

[4] D. G. Holmes, B. P. McGrath and S. G. Parker, "Current regulation strategies for vector-controlled induction motor drives," IEEE Transactions on Industrial Electronics, vol. 59, no. 10, pp. 36803689, Oct. 2012.

[5] A. Pal, S. Das and A.K. Chattopadhyay, "An improved rotor flux space vector based mras for field-oriented control of induction motor drives," IEEE Transactions on Power Electronics, vol. 33, no. 6, pp. 5131-5141, June 2018

[6] M. Popescu, A. Bitoleanu and C. V. Suru, "Synthesis of rotor field-orientation control for induction traction motor," in Proc. 2021 International Conference on Applied and Theoretical Electricity (ICATE), 2021, pp. 1-6.

[7] G. Jo and J. Choi, "Rotor field-oriented V/f drive system implementation with oscillation suppression compensator in induction motors," IEEE Journal of Emerging and Selected Topics in Power Electronics, 2020.

[8] S. Yang, R. Sun, P. Cao, Z. Xie and X. Zhang, "Sliding-mode observer based rotor resistance updating method for indirect vector controlled induction motor," in Proc. 2017 IEEE Transportation Electrification Conference and Expo, Asia-Pacific (ITEC Asia-Pacific), Harbin, China, 2017, pp. 1-5.

[9] A. Gogea, O. Stoicuta, T. Pana and A. Paramon, Comparative study a two adaptive observers of speed and rotor flux of the induction motor," in Proc. 2019 8th International Conference on Modern Power Systems (MPS), Cluj-Napoca, Cluj, Romania, 2019, pp. 1-8.

[10] S. Chacko and S. Jain, "TS -Fuzzy controller based rotor resistance estimation for indirect field oriented controlled IM drive utilizing rotor flux," in Proc. 2014 Annual IEEE India Conference (INDICON), Pune, India, 2014, pp. 1-6.

[11] D. Troncon, M. Carbonieri, L. Alberti and N. Bianchi, "Measurements and simulation of induction machines flux linkage characteristics adopting rotor field orientation," in Proc. 2020 International Conference on Electrical Machines (ICEM), Gothenburg, Sweden, 2020, pp. 225-231.

[12] H. Xie, F. Wang, W. Zhang, C. Garcia, J. Rodríguez and R. Kennel, "Sliding mode flux observer based predictive field oriented control for induction machine drives," in Proc. 2020 IEEE 9th International Power Electronics and Motion Control Conference (IPEMC2020-ECCE Asia), 2020, pp. 3021-3025.

[13] M. J. Cheerangal, A. K. Jain and A. Das, "Control of rotor fieldoriented induction motor drive during input supply voltage sag," IEEE Journal of Emerging and Selected Topics in Power Electronics, vol. 9, no. 3, pp. 2789-2796, June 2021.

[14] S. Chandran, "Neural learning algorithm based rotor resistance estimation for fuzzy logic based sensorlless IFOC of induction motor," in Proc. 2014 International Conference on Power Signals Control and Computations, Thrissur, India, 2014, pp. 1-6.

[15] T. Pană, O. C. Stoicuța, Stabilitatea sistemelor de acționare vectoriala cu motoare de inducție, Ed. Mediamira, 2016. 